\title{
Prediction and clinical utility of a contralateral breast cancer risk model
}

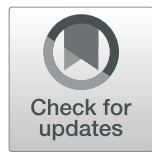

\begin{abstract}
Daniele Giardiello ${ }^{1,2}$, Ewout W. Steyerberg ${ }^{2,3}$, Michael Hauptmann ${ }^{4,5}$, Muriel A. Adank ${ }^{6}$, Delal Akdeniz ${ }^{7}$, Carl Blomqvist ${ }^{8,9}$, Stig E. Bojesen ${ }^{10,11,12}$, Manjeet K. Bolla ${ }^{13}$, Mariël Brinkhuis ${ }^{14}$, Jenny Chang-Claude ${ }^{15,16}$, Kamila Czene ${ }^{17}$, Peter Devilee ${ }^{18,19}$, Alison M. Dunning ${ }^{20}$, Douglas F. Easton ${ }^{13,20}$, Diana M. Eccles ${ }^{21}$,
\end{abstract} Peter A. Fasching 22,23, Jonine Figueroa 24,25,26, Henrik Flyger ${ }^{27}$, Montserrat García-Closas ${ }^{26,28}$, Lothar Haeberle ${ }^{23}$, Christopher A. Haiman ${ }^{29}$, Per Hall17,30, Ute Hamann ${ }^{31}$, John L. Hopper ${ }^{32}$, Agnes Jager ${ }^{33}$, Anna Jakubowska ${ }^{34,35}$, Audrey Jung ${ }^{15}$, Renske Keeman ${ }^{1}$, Iris Kramer ${ }^{1}$, Diether Lambrechts ${ }^{36,37}$, Loic Le Marchand ${ }^{38}$, Annika Lindblom ${ }^{39,40}$, Jan Lubiński ${ }^{34}$, Mehdi Manoochehri ${ }^{31}$, Luigi Mariani ${ }^{41}$, Heli Nevanlinna ${ }^{42}$, Hester S. A. Oldenburg ${ }^{43}$, Saskia Pelders ${ }^{7}$, Paul D. P. Pharoah ${ }^{13,20}$, Mitul Shah ${ }^{20}$, Sabine Siesling ${ }^{44}$, Vincent T. H. B. M. Smit ${ }^{18}$, Melissa C. Southey ${ }^{45,46}$, William J. Tapper ${ }^{47}$, Rob A. E. M. Tollenaar ${ }^{48}$, Alexandra J. van den Broek' ${ }^{1}$, Carolien H. M. van Deurzen ${ }^{49}$, Flora E. van Leeuwen ${ }^{50}$, Chantal van Ongeval ${ }^{51}$, Laura J. Van't Veer ${ }^{1}$, Qin Wang ${ }^{13}$, Camilla Wendt ${ }^{52}$, Pieter J. Westenend ${ }^{53}$, Maartje J. Hooning ${ }^{7}$ and Marjanka K. Schmidt ${ }^{1,50^{*}}$

\begin{abstract}
Background: Breast cancer survivors are at risk for contralateral breast cancer (CBC), with the consequent burden of further treatment and potentially less favorable prognosis. We aimed to develop and validate a CBC risk prediction model and evaluate its applicability for clinical decision-making.

Methods: We included data of 132,756 invasive non-metastatic breast cancer patients from 20 studies with 4682 CBC events and a median follow-up of 8.8 years. We developed a multivariable Fine and Gray prediction model (PredictCBC-1A) including patient, primary tumor, and treatment characteristics and BRCA1/2 germline mutation status, accounting for the competing risks of death and distant metastasis. We also developed a model without BRCA1/2 mutation status (PredictCBC-1B) since this information was available for only $6 \%$ of patients and is routinely unavailable in the general breast cancer population. Prediction performance was evaluated using calibration and discrimination, calculated by a time-dependent area under the curve (AUC) at 5 and 10 years after diagnosis of primary breast cancer, and an internal-external cross-validation procedure. Decision curve analysis was performed to evaluate the net benefit of the model to quantify clinical utility.

(Continued on next page)
\end{abstract}

\footnotetext{
* Correspondence: mk.schmidt@nki.nl

'Division of Molecular Pathology, The Netherlands Cancer Institute - Antoni

van Leeuwenhoek Hospital, Amsterdam, The Netherlands

${ }^{50}$ Division of Psychosocial Research and Epidemiology, The Netherlands

Cancer Institute - Antoni van Leeuwenhoek Hospital, Plesmanlaan 121, 1066,

CX, Amsterdam, The Netherlands

Full list of author information is available at the end of the article
}

(c) The Author(s). 2019 Open Access This article is distributed under the terms of the Creative Commons Attribution 4.0 International License (http://creativecommons.org/licenses/by/4.0/), which permits unrestricted use, distribution, and reproduction in any medium, provided you give appropriate credit to the original author(s) and the source, provide a link to the Creative Commons license, and indicate if changes were made. The Creative Commons Public Domain Dedication waiver (http://creativecommons.org/publicdomain/zero/1.0/) applies to the data made available in this article, unless otherwise stated. 
(Continued from previous page)

Results: In the multivariable model, BRCA1/2 germline mutation status, family history, and systemic adjuvant treatment showed the strongest associations with CBC risk. The AUC of PredictCBC-1A was 0.63 (95\% prediction interval (PI) at 5 years, 0.52-0.74; at 10 years, 0.53-0.72). Calibration-in-the-large was -0.13 (95\% PI: -1.62-1.37), and the calibration slope was 0.90 (95\% PI: 0.73-1.08). The AUC of Predict-1B at 10 years was 0.59 (95\% PI: 0.52-0.66); calibration was slightly lower. Decision curve analysis for preventive contralateral mastectomy showed potential clinical utility of PredictCBC-1A between thresholds of 4-10\% 10-year CBC risk for BRCA1/2 mutation carriers and non-carriers.

Conclusions: We developed a reasonably calibrated model to predict the risk of CBC in women of Europeandescent; however, prediction accuracy was moderate. Our model shows potential for improved risk counseling, but decision-making regarding contralateral preventive mastectomy, especially in the general breast cancer population where limited information of the mutation status in BRCA1/2 is available, remains challenging.

Keywords: Contralateral breast cancer, Risk prediction model, Clinical decision-making, BRCA mutation carriers

\section{Introduction}

Breast cancer $(\mathrm{BC})$ is a major burden for women's health [1]. Survival has improved substantially over the past half century due to earlier detection and advanced treatment modalities, for example in the Netherlands, 10-year survival of a first primary BC improved from $40 \%$ in $1961-1970$ to $79 \%$ in $2006-$ 2010 [2]. Consequently, increasing numbers of BC survivors are at risk to develop a new primary tumor in the opposite (contralateral) breast, with subsequent treatment and potentially less favorable prognosis [3]. $\mathrm{BC}$ survivors are more likely to develop contralateral breast cancer $(\mathrm{CBC})$ compared to healthy women to develop a first primary BC [4].

Women at elevated $\mathrm{CBC}$ risk have been identified to be $B R C A 1 / 2$ and $C H E K 2$ c.1100del mutation carriers and to have a $\mathrm{BC}$ family history, particularly a family history of bilateral $\mathrm{BC}$ [5-10]. For BRCA1/2 mutation carriers, in whom $C B C$ risk is high, contralateral preventive mastectomy $(\mathrm{CPM})$ is often offered [11]. However, the average risk of $\mathrm{CBC}$ among all first $\mathrm{BC}$ survivors is still relatively low, with an incidence of $\sim 0.4 \%$ per year $[12-$ 14]. Despite this, in recent years, CPM frequency has increased among women in whom CBC risk is low [15]. For these reasons, there is an urgent need for improved individualized prediction of $\mathrm{CBC}$ risk, both to facilitate shared decision-making of physicians and women regarding treatment and prevention strategies for those at high CBC risk and to avoid unnecessary CPM or surveillance mammography after first primary $B C$ when $C B C$ risk is low.

To our knowledge, only one specific CBC risk prediction model (CBCrisk) has been developed to date. CBCrisk used data on 1921 CBC cases and 5763 matched controls with validation in two independent US studies containing a mix of invasive and in situ BC $[16$, 17]. Moreover, the level of prediction performance measures such as calibration and discrimination needed for a $\mathrm{CBC}$ risk prediction to be clinically useful have not yet been addressed [18].

Our aim was twofold: first, to develop and validate a $\mathrm{CBC}$ risk prediction model using a large international series of individual patient data including 132,756 patients with a first primary invasive BC between 1990 and 2013 from multiple studies in Europe, USA, and Australia with 4682 incident CBCs, and second, to evaluate the potential clinical utility of the model to support decision-making.

\section{Material and methods \\ Study population}

We used data from five main sources: three studies from the Netherlands, 16 studies from the Breast Cancer Association Consortium (BCAC), and a cohort from the Netherlands Cancer Registry [19-22]. For details regarding data collection and patient inclusion, see Additional file 1: Data and patient selection and Table S1, and Additional file 1: Table S2. We included female patients with invasive non-metastatic first primary BC with no prior history of cancer (except for non-melanoma skin cancer). The studies were either population- or hospital-based series; most women were of Europeandescent. We only included women diagnosed after 1990 to have a population with diagnostic and treatment procedures likely close to modern practice and at the same time sufficient follow-up to study CBC incidence; in total 132,756 women from 20 studies were included. All studies were approved by the appropriate ethics and scientific review boards. All women provided written informed consent or did not object to secondary use of clinical data in accordance with Dutch legislation and codes of conduct $[23,24]$.

\section{Available data and variable selection}

Several factors have been shown or suggested to be associated with $\mathrm{CBC}$ risk, including age at first $\mathrm{BC}$, family 
history for BC, BRCA1/2 and CHEK2 c.1100del mutations, body mass index (BMI), breast density change, (neo)adjuvant chemotherapy, endocrine therapy, CPM, and characteristics of the first $\mathrm{BC}$ such as histology (lobular vs ductal), estrogen receptor (ER) status, lymph node status, tumor size, and TNM stage [5, 9, 12, 2536]. The choice of factors to include in the analyses was determined by evidence from literature, availability of data in the cohorts, and current availability in clinical practice. We extracted the following information: $B R C A 1 / 2$ germline mutation, (first degree) family history of primary $\mathrm{BC}$, and regarding primary $\mathrm{BC}$ diagnosis: age, nodal status, size, grade, morphology, ER status, progesterone receptor (PR), human epidermal growth factor receptor 2 (HER2) status, administration of adjuvant and/ or neoadjuvant chemotherapy, adjuvant endocrine therapy, adjuvant trastuzumab therapy, radiotherapy. We excluded PR status and TNM stage of the primary BC due to collinearity with ER status and the size of the primary tumor, respectively. In the current clinical practice, only patients with ER-positive tumors receive endocrine therapy and only patients with HER2-positive tumors receive trastuzumab; these co-occurrences were considered in the model by using composite categorical variables. More information is available online about the factors included in the analyses (Additional file 1: Data patient selection and Additional file 2: Figure S1), follow-up per dataset, and study design (Additional file 1: Table S2).

\section{Statistical analyses}

All analyses were performed using SAS (SAS Institute Inc., Cary, NC, USA) and R software [37].

\section{Primary endpoint, follow-up, and predictors}

The primary endpoint in the analyses was in situ or invasive metachronous $\mathrm{CBC}$. Follow-up started 3 months after invasive first primary $\mathrm{BC}$ diagnosis, in order to exclude synchronous $\mathrm{CBCs}$, and ended at date of $\mathrm{CBC}$, distant metastasis (but not at loco-regional relapse), CPM, or last date of follow-up (due to death, being lost to follow-up, or end of study), whichever occurred first. The follow-up of 27,155 (20.4\%) women from the BCAC studies, recruited more than 3 months after diagnosis of the first primary $\mathrm{BC}$ (prevalent cases), started at recruitment (left truncation). Distant metastasis and death due to any cause were considered as competing events. Patients who underwent CPM during the follow-up were censored because the $\mathrm{CBC}$ risk was almost zero after a CPM [38]. Missing data were multiply imputed by chained equations (MICE) to avoid loss of information due to case-wise deletion [39, 40]. Details about the imputation model, strategy used, and the complete case analysis are provided in Additional file 1: Multiple Imputation of missing values, complete case analysis, and model diagnostics and baseline recalibration and Additional file 1: Tables S3 and S4.

\section{Model development and validation}

For model development, we used a multivariable Fine and Gray model regression to account for death and distant metastases as competing events [41, 42]. Heterogeneity of baseline risks between studies was taken into account using the study as a stratification term. A stratified model allows the baseline subdistribution hazard to be different across the studies, and parameter estimation is performed by maximization of the partial likelihood per study. A Breslow-type estimator was used to estimate the baseline cumulative subdistribution hazard per study. The assumption of proportional subdistribution hazards was graphically checked using Schoenfield residuals [43]. The resulting subdistributional hazard ratios (sHRs) and corresponding 95\% confidence intervals (CI) were pooled from the 10 imputed data sets using Rubin's rules [44]. We built a nomogram for estimating the 5and 10-year cumulative incidence of $\mathrm{CBC}$ as a graphical representation of the multivariable risk prediction model [45].

The validity of the model was investigated by leaveone-study-out cross-validation, i.e., in each validation step, all studies are used except one in which the validity of the model is evaluated [46, 47]. Since the ABCS study and some studies from $B C A C$ had insufficient $C B C$ events required for reliable validation, we used the geographic area as unit of splitting. We had 20 studies in five main sources: 17 out of 20 studies that were combined in 4 geographic areas. In total, 3 studies and 4 geographic areas were used to assess the prediction performance of the model (see Additional file 1: Leaveone-study-out cross-validation and Additional file 1: Table S5, $[47,48]$.

The performance of the model was assessed by discrimination ability to differentiate between patients who experienced $\mathrm{CBC}$ and those who did not, and by calibration, which measures the agreement between observed and predicted CBC risk. Discrimination was quantified by time-dependent area under the ROC curves (AUCs) based on Inverse Censoring Probability Weighting at 5 and 10 years $[49,50]$. In the presence of competing risks, the R package timeROC provides two types of AUC according to a different definition of time-dependent cases and controls. AUCs were calculated considering a patient who developed a $\mathrm{CBC}$ as a case and a patient free of any event as a control at 5 and 10 years [50]. Values of AUCs close to 1 indicate good discriminative ability, while values close to 0.5 indicated poor discriminative ability. Calibration was assessed by the calibration-inthe-large and slope statistic [51]. Calibration-in-the-large lower or higher than 0 indicates that prediction is 
systematically too high or low, respectively. A calibration slope of 1.0 indicates good overall calibration; slopes below (above) 1.0 indicate over (under) estimation of risk by the model.

To allow for heterogeneity among studies, a randomeffect meta-analysis was performed to provide summaries of discrimination and calibration performance. The 95\% prediction intervals (PI) indicated the likely range for the prediction performances of the model in a new dataset. Further details about the validation process are provided in Additional file 1: Leave-one-study-out crossvalidation.

\section{Clinical utility}

The clinical utility of the prediction model was evaluated using decision curve analysis (DCA) [52, 53]. Such a decision may apply to more or less intensive screening and follow-up or to decision of a CPM. The key part of the DCA is the net benefit, which is the number of truepositive classifications (in this example: the benefit of CPM to a patient who would have developed a $\mathrm{CBC}$ ) minus the number of false-positive classifications (in this example: the harm of unnecessary CPM in a patient who would not have developed a $\mathrm{CBC}$ ). The false positives are weighted by a factor related to the relative harm of a missed $\mathrm{CBC}$ versus an unnecessary CPM. The weighting is derived from the threshold probability to develop a $\mathrm{CBC}$ using a defined landmark time point (e.g., $\mathrm{CBC}$ risk at 5 or 10 years) [54]. For example, a threshold of $10 \%$ implies that CPM in 10 patients, of whom one would develop CBC if untreated, is acceptable (thus performing 9 unnecessary CPMs). The net benefit of a prediction model is traditionally compared with the strategies of treat all or treat none. Since the use of CPM is generally only suggested among $B R C A 1 / 2$ mutation carriers, for a more realistic illustration, the decision curve analysis was reported among $B R C A 1 / 2$ mutation carriers and non-carriers [55]. See Additional file 1: Clinical utility for details.

\section{Results}

A total of 132,756 invasive primary $\mathrm{BC}$ women diagnosed between 1990 and 2013, with 4682 CBC events, from 20 studies, were used to derive the model for $\mathrm{CBC}$ risk (Additional file 1: Table S2). Median follow-up time was 8.8 years, and $\mathrm{CBC}$ cumulative incidences at 5 and

Table 1 Multivariable subdistribution hazard model for contralateral breast cancer risk

\begin{tabular}{|c|c|c|}
\hline \multirow[t]{2}{*}{ Factor (category) at primary breast cancer } & \multicolumn{2}{|c|}{ Multivariable analysis } \\
\hline & SHR & $95 \% \mathrm{Cl}$ \\
\hline Age, years & $0.68^{*}$ & $0.62-0.74^{*}$ \\
\hline Family history (yes versus no) & 1.35 & $1.27-1.45$ \\
\hline \multicolumn{3}{|l|}{$B R C A$ mutation } \\
\hline$B R C A 1$ versus non-carrier & 3.68 & $3.34-4.07$ \\
\hline$B R C A 2$ versus non-carrier & 2.56 & $2.36-2.78$ \\
\hline Nodal status (positive versus negative) & 0.87 & $0.80-0.93$ \\
\hline \multicolumn{3}{|l|}{ Tumor size, $\mathrm{cm}$} \\
\hline 2.5 versus $\leq 2$ & 0.95 & $0.89-1.02$ \\
\hline$>5$ versus $\leq 2$ & 1.14 & $0.99-1.31$ \\
\hline Morphology (lobular including mixed versus ductal including others) & 1.23 & $1.14-1.34$ \\
\hline \multicolumn{3}{|l|}{ Grade } \\
\hline Moderately differentiated versus well differentiated & 0.89 & $0.82-0.96$ \\
\hline Poorly differentiated versus well differentiated & 0.75 & $0.70-0.82$ \\
\hline Chemotherapy (yes versus no) & 0.77 & $0.70-0.84$ \\
\hline Radiotherapy to the breast (yes versus no) & 1.01 & $0.95-1.08$ \\
\hline \multicolumn{3}{|l|}{ ER (positive or negative)/endocrine therapy (yes or no) } \\
\hline Negative/no versus positive/yes & 1.43 & $1.30-1.57$ \\
\hline Positive/no versus positive/yes & 1.75 & $1.61-1.90$ \\
\hline \multicolumn{3}{|l|}{ HER2 (positive or negative)/trastuzumab therapy (yes or no) } \\
\hline Negative/no versus positive/yes & 1.08 & $0.93-1.27$ \\
\hline Positive/no versus positive/yes & 0.99 & $0.83-1.18$ \\
\hline
\end{tabular}

sHR subdistributional hazard ratio, $\mathrm{Cl}$ confidence interval, ER estrogen receptor, $H E R 2$ human epidermal growth factor receptor $2 .{ }^{*} \mathrm{Age}$ was parameterized as a linear spline with one interior knot at 50 years. For representation purposes, we here provide the sHR for the 75 th versus the 25 th percentile. For more details about age parameterization, see also Additional file 3: Supplementary Methods 
10 years were $2.1 \%$ and $4.1 \%$, respectively. Details of the studies and patient, tumor, and treatment characteristics are provided in Additional file 1: Table S6. The multivariable model with estimates for all included factors is shown in Table 1 and Additional file 3. BRCA1/2 germline mutation status, family history, and systemic adjuvant treatment showed the strongest associations with $\mathrm{CBC}$ risk.

The prediction performance of the main model (PredictCBC, version $1 \mathrm{~A}$ ) based on the leave-one-study-out cross-validation method is shown in Fig. 1. The AUC at 5 years was 0.63 (95\% confidence interval (CI): $0.58-$ 0.67; 95\% prediction interval (PI): $0.52-0.74)$ ); the AUC at 10 years was also 0.63 (95\% CI: $0.59-0.66$; $95 \%$ PI: 0.53-0.72). Calibrations showed some indications of overestimation of risk. The calibration-in-the-large was - 0.13 (95\% CI: $-0.66-0.40$; 95\% PI: $-1.62-1.37$ ). The calibration slope was 0.90 (95\% CI: $0.79-1.02$; $95 \%$ PI: $0.73-1.08)$ in the cross-validation. Calibration plots are provided in Additional file 2: Figure S2 and S3.
The nomogram representing a graphical tool for estimating the $\mathrm{CBC}$ cumulative incidence at 5 and 10 years based on our model and the estimated baseline of the Dutch Cancer Registry is shown in Fig. 2. In the nomogram, the categories of each factor are assigned a score using the topmost "Points" scale, then all scores are summed up to obtain the "Total points", which relate to the cumulative incidence of $\mathrm{CBC}$. The formulae of the models (PredictCBC-1A and 1B) providing the predicted cumulative incidence are given in Additional file 1: Formula to estimate the $\mathrm{CBC}$ risk and formula to estimate $\mathrm{CBC}$ risk in patients not tested for $B R C A$.

The DCAs for preventive contralateral mastectomy showed the potential clinical utility of PredictCBC-1A between thresholds of 4-10\% 10-year CBC risk for BRCA1/2 mutation carriers and non-carriers (Table 2 and Additional file 3). For example, if we find it acceptable that one in 10 patients for whom a CPM is recommended develops a $\mathrm{CBC}$, a risk threshold of $10 \%$ may be used to define high and low risk $B R C A 1 / 2$ mutation

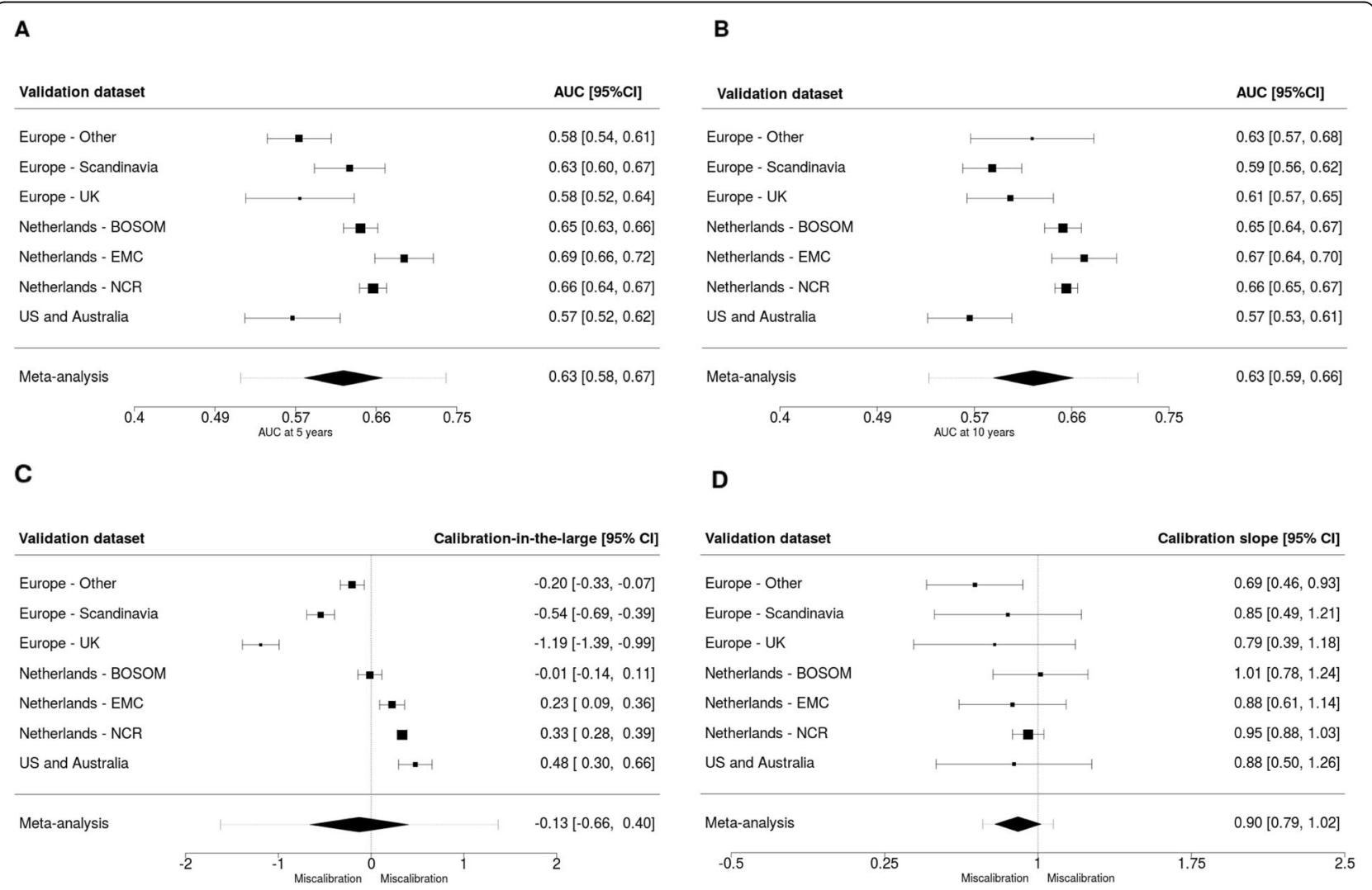

Fig. 1 Analysis of predictive performance in leave-one-study-out cross-validation. $\mathbf{a}$, b The discrimination assessed by a time-dependent AUC at 5 and 10 years, respectively. $\mathbf{c}$ The calibration accuracy measured with calibration-in-the-large. $\mathbf{d}$ The calibration accuracy measured with calibration slope. The black squares indicate the estimated accuracy of a model built using all remaining studies or geographic areas. The black horizontal lines indicate the corresponding 95\% confidence intervals of the estimated accuracy (interval whiskers). The black diamonds indicate the mean with the corresponding 95\% confidence intervals of the predictive accuracy, and the dashed horizontal lines indicate the corresponding $95 \%$ prediction intervals 


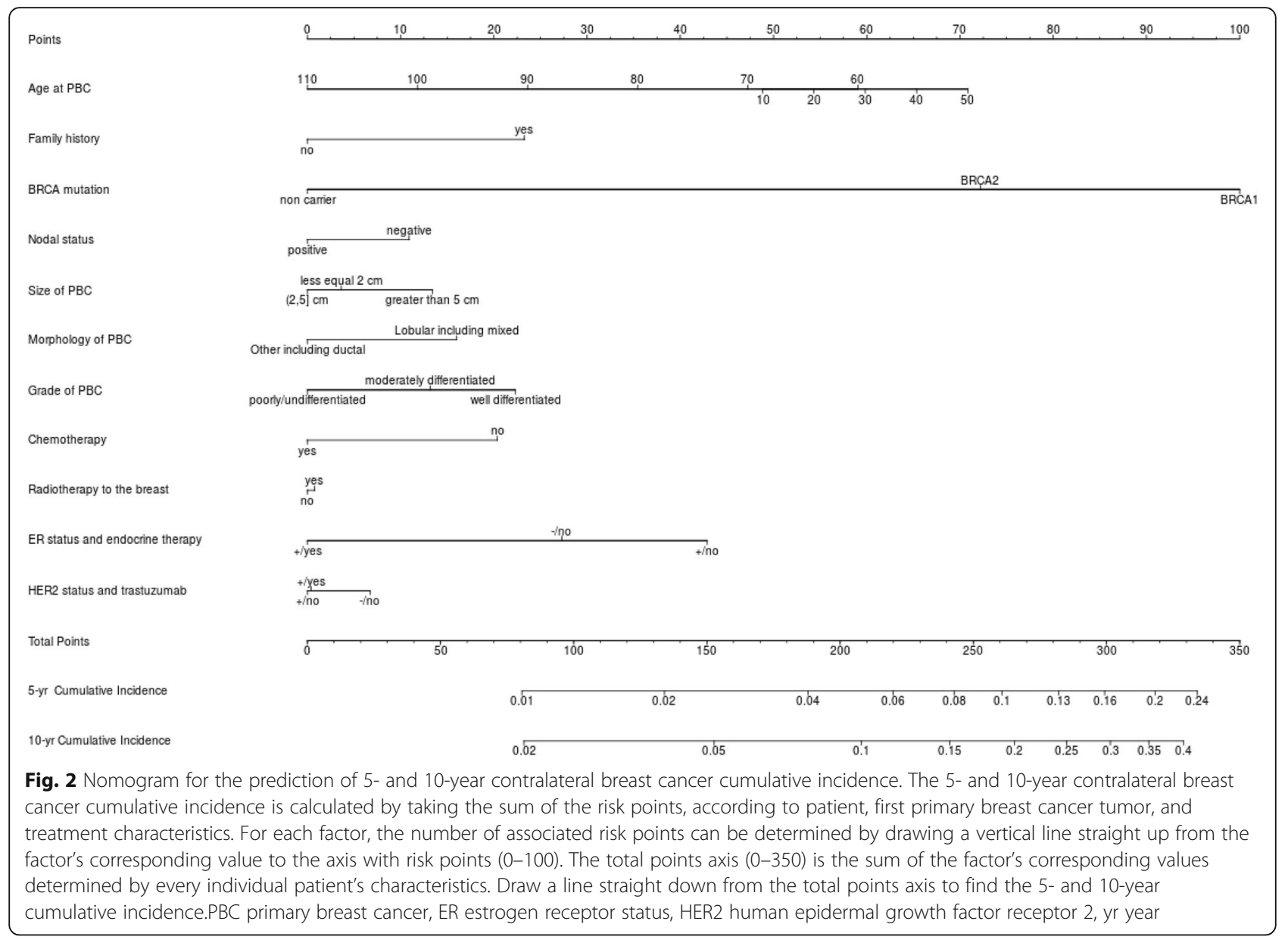

carriers based on the absolute 10-year CBC risk prediction estimated by the model. Compared with a strategy recommending CPM to all carriers of a mutation in $B R C A 1 / 2$, this strategy avoids 161 CPMs per 1000 patients. In contrast, almost no non $B R C A 1 / 2$ mutation carriers reach the $10 \%$ threshold (the general $\mathrm{BC}$ population, Fig. 3). The decision curves provide a comprehensive overview of the net benefit for a range of harm-benefit thresholds at 10-year CBC risk (Fig. 4).

Decision curves for $\mathrm{CBC}$ risk at 5 year and the corresponding clinical utility are provided in Additional file 2: Figure S4 and Additional file 1: Table S7, respectively.

Table 2 Clinical utility of the 10-year contralateral breast cancer risk prediction model. At the same probability threshold, the net benefit is exemplified in BRCA1/2 mutation carriers (for avoiding unnecessary CPM) and non-carriers (performing necessary CPM)

\begin{tabular}{|c|c|c|c|c|c|}
\hline \multirow{2}{*}{$\begin{array}{l}\text { Probability } \\
\text { threshold, } \\
p_{\mathrm{t}}(\%)\end{array}$} & \multirow{2}{*}{$\begin{array}{l}\text { Unnecessary } \\
\text { CPMs } \\
\text { needed to } \\
\text { prevent one } \\
\text { CBC }^{*}\end{array}$} & \multicolumn{2}{|l|}{ BRCA1/2 mutation carriers } & \multicolumn{2}{|l|}{ Non-carriers } \\
\hline & & $\begin{array}{l}\text { Net benefit versus treat all patients } \\
\text { with CPM (per 1000) }\end{array}$ & $\begin{array}{l}\text { Avoided unnecessary CPMs } \\
\text { per } 1000 \text { patients }\end{array}$ & $\begin{array}{l}\text { Net benefit versus treat } \\
\text { none (per 1000) }\end{array}$ & $\begin{array}{l}\text { Performed necessary CPMs } \\
\text { per } 1000 \text { patients }\end{array}$ \\
\hline 4 & 24.0 & 0.0 & 0.0 & 3.9 & 93.6 \\
\hline 5 & 19.0 & 0.0 & 0.0 & 2.1 & 39.9 \\
\hline 6 & 15.7 & 0.1 & 1.6 & 0.5 & 7.8 \\
\hline 7 & 13.3 & 1.9 & 25.2 & 0.1 & 1.3 \\
\hline 8 & 11.5 & 5.5 & 63.3 & 0.0 & 0.0 \\
\hline 9 & 10.1 & 10.7 & 108.2 & 0.0 & 0.0 \\
\hline 10 & 9.0 & 17.9 & 161.1 & 0.0 & 0.0 \\
\hline
\end{tabular}

CPM contralateral preventive mastectomy, $C B C$ contralateral breast cancer. ${ }^{*}$ The number of unnecessary contralateral mastectomies needed to prevent a CBC is calculated by $\left(1-p_{\mathrm{t}}\right) / p_{\mathrm{t}}$. See also Additional file 3 : Methods 


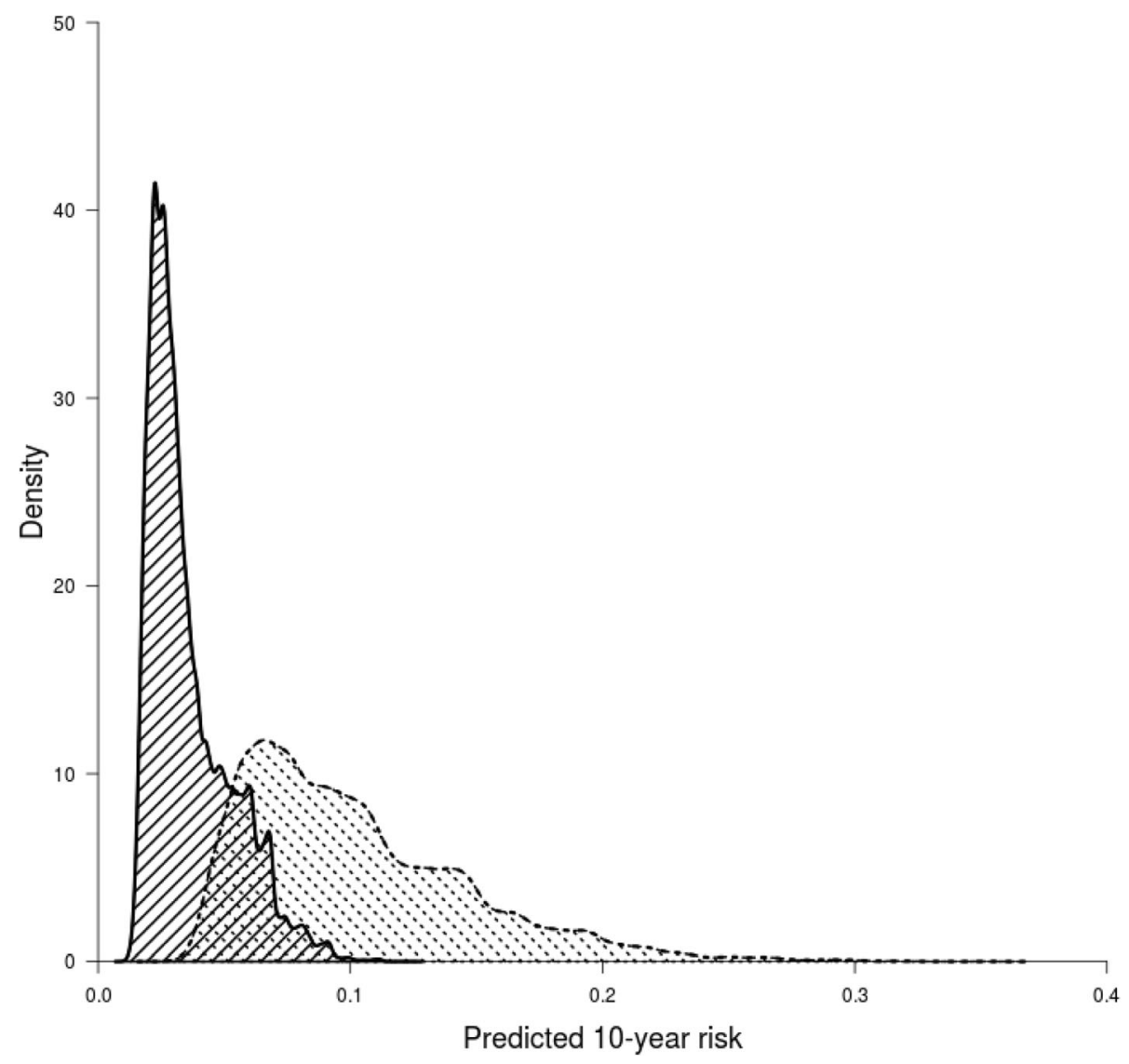

Fig. 3 Density distribution of 10-year predicted contralateral breast cancer absolute risk within non-carriers (area with black solid lines) and BRCA1/2 mutation carriers (area with black dashed lines)

We also derived a risk prediction model (PredictCBC, version $1 \mathrm{~B}$ ) omitting $B R C A$ status to provide $\mathrm{CBC}$ risk estimates for first $\mathrm{BC}$ patients not tested for $B R C A 1 / 2$ mutations. This model has slightly lower prediction performance; AUC at 5 and 10 years was both 0.59 (at 5 years: 95\% CI: 0.54-0.63, 95\% PI: $0.46-0.71$; at 10 years: 95\% CI: $0.56-0.62$, 95\% PI: 0.52-0.66), calibration-in-the-large was 0.17 (95\% CI: $-0.72-0.38$; 95\% PI: $-1.70-1.36$ ), and calibration slope was 0.81 (95\% CI $0.63-0.99 ; 95 \%$ PI: 0.50-1.12) (Additional file 1: Results of the prediction model without BRCA mutation). Details of development, validation, and clinical utility are provided in Additional file 1: Tables S8-S10 and Figure S5-S10.

In a sensitivity analysis (see Additional file 1: Assessment of limited information of (PM), we studied the impact of CPM on our results using two studies, in which CPM information was (almost) completely available. The lack of CPM information on cumulative incidence estimation hardly affected the results of our analyses (Additional file 2: Figure S11).

\section{Discussion}

Using established risk factors for $\mathrm{CBC}$ which are currently available in clinical practice, we developed PredictCBC, which can be used to calculate 5- and 10-year absolute $\mathrm{CBC}$ risk. The risk prediction model includes carriership of BRCA1/2 mutations, an important determinant of $\mathrm{CBC}$ risk in the decision-making process [6].

The calibration of the model was reasonable and discrimination moderate within the range of other tools commonly used for routing counseling and decisionmaking in clinical oncology for primary BC risk [56-59]. As expected, the prediction accuracy was lower when we omitted the $B R C A$ mutation carrier status although the prevalence of $B R C A$ mutations among $\mathrm{BC}$ patients is quite low $(2-4 \%)$ [60, 61].

In the breast cancer population, $\mathrm{CBC}$ is a relatively uncommon event $(\sim 0.4 \%$ per year) and difficult to predict. Therefore, physicians should carefully consider which patients should consider CPM using a prediction model [62]. The current clinical recommendations of CPM are essentially based on the presence of a mutation in the $B R C A 1 / 2$ genes. Based on the risk distribution defined 
A

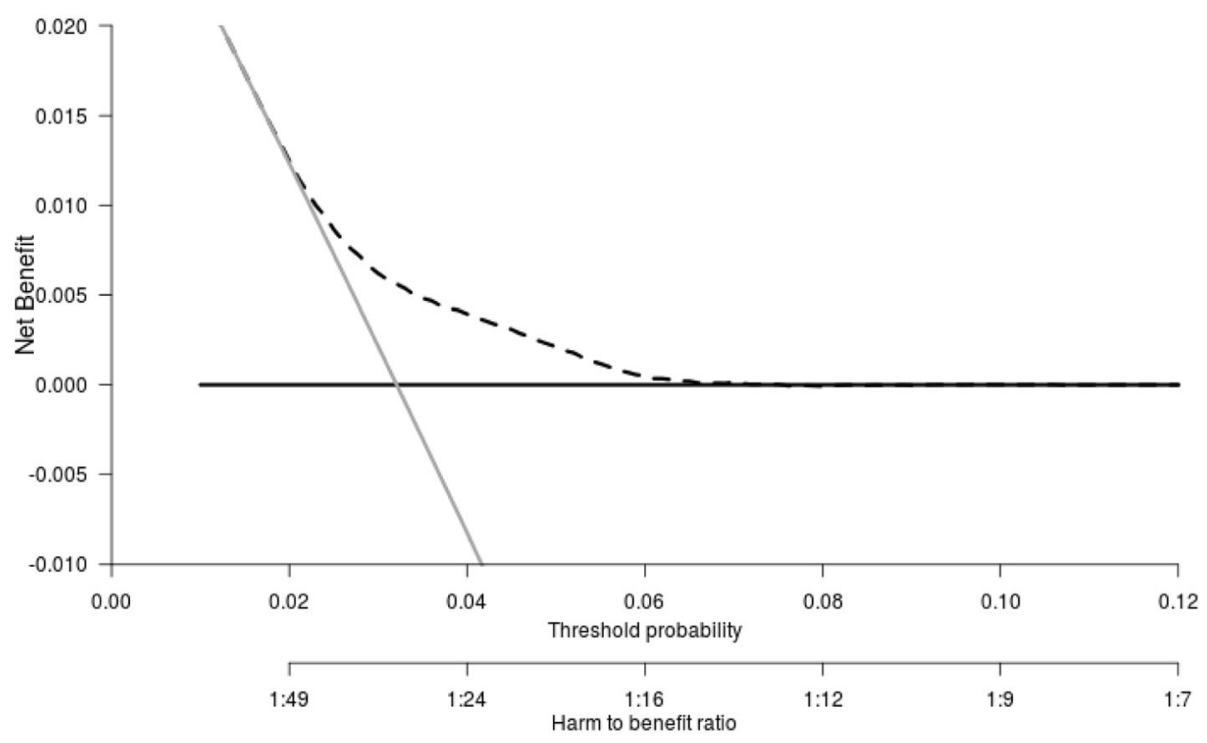

B

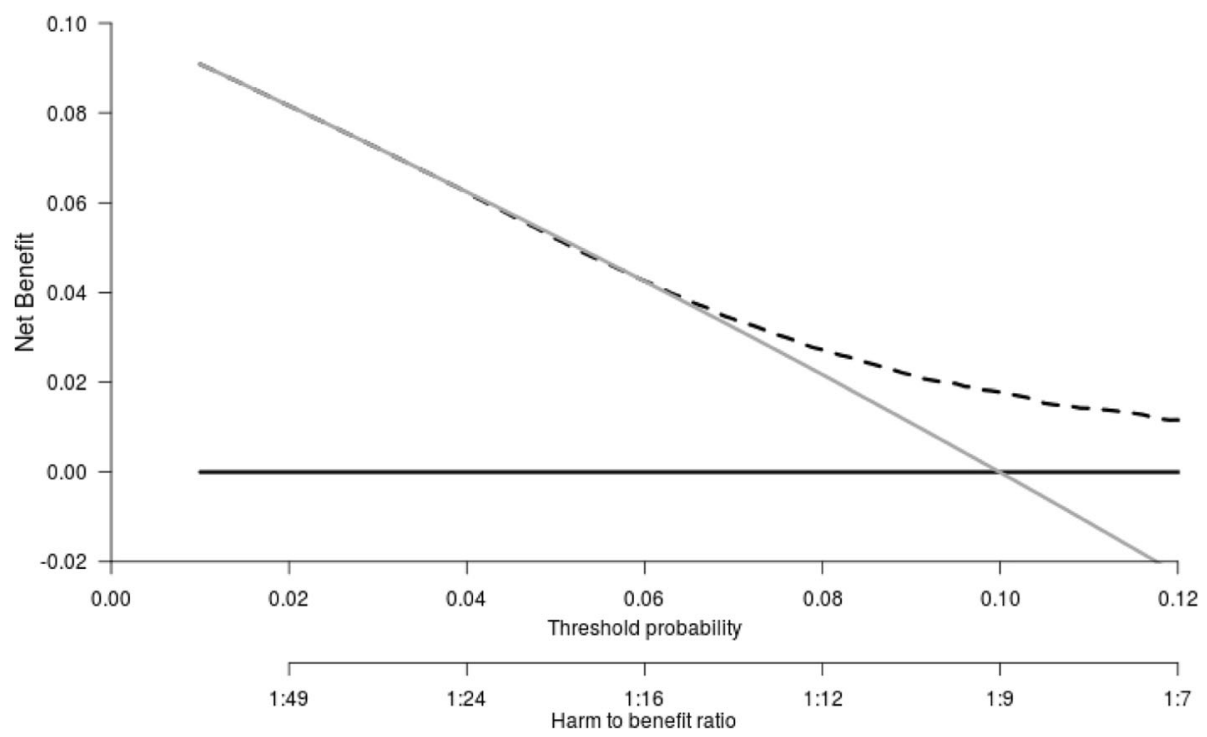

Fig. 4 Decision curve analysis at 10 years for the contralateral breast cancer risk model including BRCA mutation information. a The decision curve to determine the net benefit of the estimated 10-year predicted contralateral breast cancer (CBC) cumulative incidence for patients without a BRCA1/2 gene mutation using the prediction model (dotted black line) compared to not treating any patients with contralateral preventive mastectomy (CPM) (black solid line). b The decision curve to determine the net benefit of the estimated 10-year predicted CBC cumulative incidence for BRCA1/2 mutation carriers using the prediction model (dotted black line) versus treating (or at least counseling) all patients (gray solid line). The $y$-axis measures net benefit, which is calculated by summing the benefits (true positives, i.e., patients with a CBC who needed a CPM) and subtracting the harms (false positives, i.e., patients with CPM who do not need it). The latter are weighted by a factor related to the relative harm of a non-prevented CBC versus an unnecessary CPM. The factor is derived from the threshold probability to develop a CBC at 10 years at which a patient would opt for CPM (e.g., 10\%). The $x$-axis represents the threshold probability. Using a threshold probability of $10 \%$ implicitly means that CPM in 10 patients of whom one would develop a CBC if untreated is acceptable ( 9 unnecessary CPMs, harm to benefit ratio 1:9)

by the current model (Fig. 3), this is a reasonable approach: essentially no non-carrier women reach a $10 \%$ risk 10 -year threshold. However, more than $50 \%$ of carriers do not reach this threshold either, suggesting that a significant proportion of $B R C A 1 / 2$ carriers might be spared CPM. Contralateral surveillance mammography may also be avoided although detection and knowledge of recurrences may be necessary for better defined 
individualized follow-up and patient-tailored treatment strategies [63, 64].

$\mathrm{CBC}$ risk patterns and factors were identified previously in a large population-based study with 10,944 CBC of 212,630 patients from the Surveillance, Epidemiology and End Results (SEER) database diagnosed from 1990 to 2013 [65]. However, SEER does not include details of endocrine treatment and chemotherapy, therapies administrated to reduce recurrences and $\mathrm{CBCs}[13,66]$. Furthermore, in this study, the model was not validated or evaluated based on prediction accuracy, nor was a tool provided. Another study provided general guidelines for CPM by calculating the lifetime risk of CBC based on a published systematic review of age at first $B C$, $B R C A 1 / 2$ gene mutation, family history of $\mathrm{BC}$, ER status, ductal carcinoma in situ, and oophorectomy [34, 67]. However, the authors specified that the calculation of the $\mathrm{CBC}$ lifetime risk should be considered only as a guide for helping clinicians to stratify patients into risk categories rather than a precise tool for the objective assessment of the risk.

Only one other prediction model (CBCrisk) has been developed and validated using data of 1921 CBC cases and 5763 matched controls [16]. External validation of CBCrisk of two independent datasets using 5185 and 6035 patients with 111 and 117 CBC assessed a discrimination between 0.61 and 0.65 [17]. The discrimination of our PredictCBC model at 5 and 10 years was similar; however, the geographic diversity of the studies gave a more complete overview of external validity [47]. Moreover, we showed the net benefit of our model using decision curve analysis since standard performance metrics of discrimination, calibration, sensitivity, and specificity alone are insufficient to assess the clinical utility $[18,53]$.

Some limitations of our study must be recognized. First, reporting of $\mathrm{CBC}$ was not entirely complete in all studies and information about CPM was limited in most datasets, which may have underestimated the cumulative incidence, although the overall 10-year cumulative incidence of $4.1 \%$ is in line with other data [5, 34]. Second, some women included in the Dutch studies (providing specific information on family history, BRCA mutation, or CPM) were also present in our selection of the Netherlands Cancer Registry population. Privacy and coding issues prevented linkage at the individual patient level, but based on the hospitals from which the studies recruited, and the age and period criteria used, we calculated a maximum potential overlap of $3.4 \%$. Third, in the US and Australian datasets, the prediction performance was uncertain due to the limited sample size and missing values. Moreover, some important predictors such as family history and especially $B R C A$ mutation status were only available in a subset of the women (from familial- and unselected hospital-based studies) and patients with data on BRCA mutation status might have been insufficiently represented for tested populations and further development and validation of PredictCBC-1A will be necessary. However, although $B R C A 1 / 2$ mutation information was unavailable in $94 \%$ of our data, the approach of the imputation led to consistently good performing models [68-70]. The remaining factors were quite complete: $\sim 79 \%$ of patients had at most one missing factor, which provided good imputation diagnostic performances. Since most BC patients are not currently tested in the clinical practice for $B R C A 1 / 2$ mutations, we assessed the clinical utility of PredictCBC version $1 \mathrm{~B}$ to provide individualized $\mathrm{CBC}$ risk estimates for first $\mathrm{BC}$ patients not tested for $B R C A 1 / 2$ germline mutations [60, 71]. Our PredictCBC version $1 \mathrm{~B}$ model provides less precise estimates, but may be useful in providing general $\mathrm{CBC}$ risk estimates, which could steer women away from CPM or trigger BRCA testing.

Last but not the least, adequate presentation of the risk estimates from the PredictCBC-1A and PredictCBC$1 \mathrm{~B}$ is crucial for effective communication about $\mathrm{CBC}$ risk during doctor-patient consultations [72, 73]. A nomogram is an important component to communicate the risk of modern medical decision-making, although it may be difficult to use and might potentially make it more difficult to interpret the risks for laymen [74] An online tool is being implemented, and a pilot study will be conducted among patients and clinicians to assess how the risk estimates from PredictCBC-1A and $1 \mathrm{~B}$ can best be visualized to facilitate communication with patients. Other factors, which were not available in our study, predict breast cancer risk and their inclusion may further improve the discrimination and clinical utility of our $\mathrm{CBC}$ risk model: these factors include CHEK2 c.1100del mutation carriers, polygenic risk scores based on common genetic variants, breast density, and reproductive and lifestyle factors such as BMI and age at menarche [75]. Additional data with complete information of BRCA1/2 mutation should be also considered in the model upgrade to reduce uncertainty of $\mathrm{CBC}$ risk estimates. External validation in other studies, including patients of other ethnicities, will also be important. In the meantime, our model provides a reliable basis for $\mathrm{CBC}$ risk counseling.

\section{Conclusions}

In conclusion, we have developed and cross-validated risk prediction models for CBC (PredictCBC) based on different European-descent population and hospitalbased studies. The model is reasonably calibrated and prediction accuracy is moderate. The clinical utility assessment of PredictCBC showed potential for improved risk counseling, although the decision regarding CPM in 
the general breast cancer population remains challenging. Similar results have been found for PredictCBC version $1 \mathrm{~B}$, a $\mathrm{CBC}$ risk prediction model that calculates individualized $\mathrm{CBC}$ risk for first $\mathrm{BC}$ patients not tested for $B R C A 1 / 2$ germline mutation.

\section{Supplementary information}

Supplementary information accompanies this paper at https://doi.org/10. 1186/s13058-019-1221-1.

\section{Additional file 1 Table S1. Data source flowchart. Table S2.} Description of the studies included in the analyses. Table S3. Patients and first primary breast cancer characteristics used in the contralateral breast cancer risk prediction model in the complete case and all case analyses. Table S4. Results of multivariable subdistributional hazard model using the complete case dataset. Table S5. List of BCAC studies (including ABCS source) with the corresponding country and geographic area. Table S6. Main patient and disease characteristics. Table S7. Clinical utility of the 5 -year contralateral breast cancer risk prediction model. Table S8. Results of multivariable subdistributional hazard model for breast cancer patients without BRCA mutations. Table S9. Clinical utility of the 5-year contralateral breast cancer risk prediction model in nonBRCA tested patients. Table S10. Clinical utility of the 10-year contralateral breast cancer risk prediction model in non-BRCA tested patients.

Additional file 2 Figure S1. Graphical assessment of non-linear relationship of age with contralateral breast cancer risk. Figure S2. Visual assessment of calibration through calibration plots in the internal-external cross-validation at 5 years for the contralateral breast cancer risk model with BRCA mutation information. Figure S3. Visual assessment of calibration through calibration plots in the internal-external cross-validation at 10 years for the contralateral breast cancer risk model with BRCA mutation information. Figure S4. Decision curve analysis at 5 years for the contralateral breast cancer risk model including BRCA1/2 mutation information. Figure S5. Results of the leave-one-study-out cross-validation for the contralateral breast cancer risk model at 5 and 10 years without BRCA mutation information. Figure S6. Visual assessment of calibration through calibration plots in the internal-external cross-validation at 5 years for the contralateral breast cancer risk model without BRCA mutation information. Figure S7. Visual assessment of calibration through calibration plots in the internal-external cross-validation at 10 years for the contralateral breast cancer risk model without BRCA mutation information. Figure S8. Density distribution of 10-year predicted absolute risk in patients with no family history and patients with a family history. Figure S9. Decision curve analysis at 5 years for the contralateral breast cancer risk model without BRCA mutation information. Figure S10. Decision curve analysis at 10 years for the contralateral breast cancer risk model without BRCA mutation information. Figure S11. Assessment of inclusion of information of contralateral preventive mastectomy (CPM).

Additional file 3. Supplementary methods.

\section{Abbreviations}

AUC: Area under the ROC curve; BC: Breast cancer; BCAC: Breast Cancer Association Consortium; BMI: Body mass index; CBC: Contralateral breast cancer; Cl: Confidence interval; CPM: Contralateral preventive mastectomy; DCA: Decision curve analysis; ER: Estrogen receptor; HER2: Human epidermal growth receptor 2; MICE: Multiple imputation by chained equations; PI: Prediction interval; PR: Progesterone receptor; SEER: Surveillance, Epidemiology and End Results; TNM: TNM Classification of Malignant Tumors

\section{Acknowledgements}

We thank all individuals who took part in these studies and all researchers, clinicians, technicians, and administrative staff who have enabled this work to be carried out.

ABCFS thank Maggie Angelakos, Judi Maskiell, Gillian Dite. ABCS and BOSOM thanks all the collaborating hospitals and pathology departments and many individual that made this study possible; specifically, we wish to acknowledge Annegien Broeks, Sten Cornelissen, Frans Hogervorst, Laura van 't Veer, Floor van Leeuwen, Emiel Rutgers. EMC thanks J.C. Blom-Leenheer, P.J. Bos, C.M.G. Crepin, and M. van Vliet for the data management. CGPS thanks staff and participants of the Copenhagen General Population Study. For the excellent technical assistance: Dorthe Uldall Andersen, Maria Birna Arnadottir, Anne Bank, Dorthe Kjeldgård Hansen. HEBCS thanks Taru A. Muranen, Kristiina Aittomäki, Karl von Smitten, and Irja Erkkilä. KARMA thanks the Swedish Medical Research Counsel. LMBC thanks Gilian Peuteman, Thomas Van Brussel, EvyVanderheyden, and Kathleen Corthouts. MARIE thanks Petra Seibold, Dieter Flesch-Janys, Judith Heinz, Nadia Obi, Alina Vrieling, Sabine Behrens, Ursula Eilber, Muhabbet Celik, Til Olchers, and Stefan Nickels. ORIGO thanks E. Krol-Warmerdam, and J. Blom for patient accrual, administering questionnaires, and managing clinical information. The authors thank the registration team of the Netherlands Comprehensive Cancer Organisation (IKNL) for the collection of data for the Netherlands Cancer Registry as well as IKNL staff for scientific advice. PBCS thanks Louise Brinton, Mark Sherman, Neonila Szeszenia-Dabrowska, Beata Peplonska, Witold Zatonski, Pei Chao, and Michael Stagner. The ethical approval for the POSH study is MREC /00/6/ 69, UKCRN ID: 1137. We thank the SEARCH team.

\section{Authors' contributions}

MKS and MJH conceived the study in collaboration with EWS and MH. DG performed the statistical analysis. DG, MKS, MJH, EWS, and MH interpreted the results and drafted the manuscript. MAA, DA, CB, SEB, MKB, MB, JCC, KC, PD,AMD, DFE, DME, PAF, JF,HF,MGC,LK, CAH, PH, UH, JLH, AG, AJ1, AJ2, RK, IK, DL, LLM, AL, JL, MM, LM, HN, HSAO, SP, PDPP, MS, SS, VTHBMS, MCS, WJT, RAEMT, AJvB, CHMvD, FEvL, CVO, LJVV, QW, CW, and PJW contributed to the critical revision and editing of the final version of the manuscript for publication. All authors were involved in the data generation or provision and read and approved the final manuscript.

\section{Funding}

This work is supported by the Alpe d'HuZes/Dutch Cancer Society (KWF Kankerbestrijding) project 6253.

BCAC is funded by Cancer Research UK [C1287/A16563, C1287/A10118], the European Union's Horizon 2020 Research and Innovation Programme (grant numbers 634935 and 633784 for BRIDGES and B-CAST respectively), and the European Community's Seventh Framework Programme under grant agreement number 223175 (grant number HEALTH-F2-2009-223175) (COGS). The EU Horizon 2020 Research and Innovation Programme funding source had no role in the study design, data collection, data analysis, data interpretation, or writing of the report.

The Australian Breast Cancer Family Study (ABCFS) was supported by grant UM1 CA164920 from the National Cancer Institute (USA). The ABCFS was also supported by the National Health and Medical Research Council of Australia, the New South Wales Cancer Council, the Victorian Health Promotion Foundation (Australia), and the Victorian Breast Cancer Research Consortium. J.L.H. is a National Health and Medical Research Council (NHMRC) Senior Principal Research Fellow. M.C.S. is a NHMRC Senior Research Fellow. The ABCS study was supported by the Dutch Cancer Society [grants NKI 20073839; 2009 4363]. The work of the BBCC was partly funded by ELAN-Fond of the University Hospital of Erlangen. BOSOM was supported by the Dutch Cancer Society grant numbers DCS-NKI 2001-2423, DCS-NKI 2007-3839, and DCSNKI 2009-4363; the Cancer Genomics Initiative; and notary office Spier \& Hazenberg for the coding procedure. The EMC was supported by grants from Alpe d'HuZes/Dutch Cancer Society NKI2013-6253 and from Pink Ribbon 2012.WO39.C143. The HEBCS was financially supported by the Helsinki University Hospital Research Fund, the Finnish Cancer Society, and the Sigrid Juselius Foundation.

Financial support for KARBAC was provided through the regional agreement on medical training and clinical research (ALF) between Stockholm County Council and Karolinska Institutet, the Swedish Cancer Society, The Gustav V Jubilee foundation and Bert von Kantzows foundation. The KARMA study was supported by Märit and Hans Rausings Initiative Against Breast Cancer. LMBC is supported by the 'Stichting tegen Kanker'. The MARIE study was supported by the Deutsche Krebshilfe e.V. [70-2892-BR I, 106332, 108253, 108419, 110826, 110828], the Hamburg Cancer Society, the German Cancer Research Center (DKFZ) and the Federal Ministry of Education and Research (BMBF) Germany [01KH0402]. MEC was supported by NIH grants CA63464, CA54281, CA098758, CA132839, and CA164973. The ORIGO study was supported by the Dutch Cancer Society (RUL 1997-1505) and the Biobanking and Biomolecular Resources Research Infrastructure (BBMRI-NL CP16). The 
PBCS was funded by Intramural Research Funds of the National Cancer Institute, Department of Health and Human Services, USA. Genotyping for PLCO was supported by the Intramural Research Program of the National Institutes of Health, $\mathrm{NCl}$, Division of Cancer Epidemiology and Genetics. The POSH study is funded by Cancer Research UK (grants C1275/A11699, C1275/ C22524, C1275/A19187, C1275/A15956) and Breast Cancer Campaign 2010PR62, 2013PR044. PROCAS is funded from NIHR grant PGFAR 070710031. SEARCH is funded by Cancer Research UK [C490/A10124, C490/ A16561] and supported by the UK National Institute for Health Research Biomedical Research Centre at the University of Cambridge. SKKDKFZS is supported by the DKFZ. The SZBCS (Szczecin Breast Cancer Study) was supported by Grant PBZ_KBN_122/P05/2004 and The National Centre for Research and Development (NCBR) within the framework of the international ERA-NET TRANSAN JTC 2012 application no. Cancer 12-054 (Contract No. ERA-NET-TRANSCAN / 07/2014).

\section{Availability of data and materials}

All data relevant to this report are included in this published article and its supplementary information files. The datasets analyzed during the current study are not publicly available due to protection of participant privacy and confidentiality, and ownership of the contributing institutions, but may be made available in an anonymized form via the corresponding author on reasonable request and after approval of the involved institutions.

\section{Ethics approval and consent to participate}

Each study was approved by its institutional ethical review board.

\section{Consent for publication}

Not applicable.

\section{Competing interests}

The authors declare that they have no competing interests.

\section{Author details}

${ }^{1}$ Division of Molecular Pathology, The Netherlands Cancer Institute - Antoni van Leeuwenhoek Hospital, Amsterdam, The Netherlands. 'Department of Biomedical Data Sciences, Leiden University Medical Center, Leiden, The Netherlands. ${ }^{3}$ Department of Public Health, Erasmus MC Cancer Institute, Rotterdam, The Netherlands. ${ }^{4}$ Institute of Biometry and Registry Research, Brandenburg Medical School, Neuruppin, Germany. ${ }^{5}$ Department of Epidemiology and Biostatistics, The Netherlands Cancer Institute - Antoni van Leeuwenhoek Hospital, Amsterdam, The Netherlands. ${ }^{6}$ The Netherlands Cancer Institute - Antoni van Leeuwenhoek hospital, Family Cancer Clinic, Amsterdam, The Netherlands. ${ }^{7}$ Department of Medical Oncology, Family Cancer Clinic, Erasmus MC Cancer Institute, Rotterdam, The Netherlands. ${ }^{8}$ Department of Oncology, Helsinki University Hospital, University of Helsinki, Helsinki, Finland. 'Department of Oncology, Örebro University Hospital, Örebro, Sweden. ${ }^{10}$ Copenhagen General Population Study, Herlev and Gentofte Hospital, Copenhagen University Hospital, Herlev, Denmark. ${ }^{11}$ Department of Clinical Biochemistry, Herlev and Gentofte Hospital, Copenhagen University Hospital, Herlev, Denmark. ${ }^{12}$ Faculty of Health and Medical Sciences, University of Copenhagen, Copenhagen, Denmark.

${ }^{13}$ Centre for Cancer Genetic Epidemiology, Department of Public Health and Primary Care, University of Cambridge, Cambridge, UK. ${ }^{14}$ East-Netherlands, Laboratory for Pathology, Hengelo, The Netherlands. ${ }^{15}$ Division of Cancer Epidemiology, German Cancer Research Center (DKFZ), Heidelberg, Germany. ${ }^{16}$ Cancer Epidemiology Group, University Cancer Center Hamburg (UCCH), University Medical Center Hamburg-Eppendorf, Hamburg, Germany. ${ }^{17}$ Department of Medical Epidemiology and Biostatistics, Karolinska Institute, Stockholm, Sweden. ${ }^{18}$ Department of Pathology, Leiden University Medical Center, Leiden, The Netherlands. ${ }^{19}$ Department of Human Genetics, Leiden University Medical Center, Leiden, The Netherlands. ${ }^{20}$ Centre for Cancer Genetic Epidemiology, Department of Oncology, University of Cambridge, Cambridge, UK. ${ }^{21}$ Cancer Sciences Academic Unit, Faculty of Medicine, University of Southampton, Southampton, UK. ${ }^{22}$ Department of Medicine Division of Hematology and Oncology, University of California at Los Angeles, David Geffen School of Medicine, Los Angeles, CA, USA. ${ }^{23}$ Department of Gynecology and Obstetrics, Comprehensive Cancer Center ER-EMN, University Hospital Erlangen, Friedrich-Alexander-University Erlangen-Nuremberg, Erlangen, Germany. ${ }^{24}$ Usher Institute of Population Health Sciences and Informatics, The University of Edinburgh Medical School,
Edinburgh, UK. ${ }^{25}$ Cancer Research UK Edinburgh Centre, Edinburgh, UK. ${ }^{26}$ Department of Health and Human Services, Division of Cancer Epidemiology and Genetics, National Cancer Institute, National Institutes of Health, Bethesda, MD, USA. ${ }^{27}$ Department of Breast Surgery, Herlev and Gentofte Hospital, Copenhagen University Hospital, Herlev, Denmark. ${ }^{28}$ Division of Genetics and Epidemiology, Institute of Cancer Research, London, UK. ${ }^{29}$ Department of Preventive Medicine, Keck School of Medicine, University of Southern California, Los Angeles, CA, USA. ${ }^{30}$ Department of Oncology, Södersjukhuset, Stockholm, Sweden. ${ }^{31}$ Molecular Genetics of Breast Cancer, German Cancer Research Center (DKFZ), Heidelberg, Germany. ${ }^{32}$ Centre for Epidemiology and Biostatistics, Melbourne School of Population and Global Health, The University of Melbourne, Melbourne, Victoria, Australia. ${ }^{33}$ Department of Medical Oncology, Erasmus MC Cancer Institute, Rotterdam, The Netherlands. ${ }^{34}$ Department of Genetics and Pathology, Pomeranian Medical University, Szczecin, Poland. ${ }^{35}$ Independent Laboratory of Molecular Biology and Genetic Diagnostics, Pomeranian Medical University, Szczecin, Poland. ${ }^{36}$ VIB Center for Cancer Biology, VIB, Leuven, Belgium. ${ }^{37}$ Laboratory for Translational Genetics, Department of Human Genetics, University of Leuven, Leuven, Belgium. ${ }^{38}$ University of Hawaii Cancer Center, Epidemiology Program, Honolulu, HI, USA. ${ }^{39}$ Department of Molecular Medicine and Surgery, Karolinska Institutet, Stockholm, Sweden. ${ }^{40}$ Department of Clinical Genetics, Karolinska University Hospital, Stockholm, Sweden. ${ }^{41}$ Unit of Clinical Epidemiology and Trial Organization, Fondazione IRCCS Istituto Nazionale dei Tumori, Milan, Italy. ${ }^{42}$ Department of Obstetrics and Gynecology, Helsinki University Hospital, University of Helsinki, Helsinki, Finland. ${ }^{43}$ Department of Surgical Oncology, The Netherlands Cancer Institute - Antoni van Leeuwenhoek Hospital, Amsterdam, The Netherlands. ${ }^{44}$ Department of Research, Netherlands Comprehensive Cancer Organisation, Utrecht, The Netherlands. ${ }^{45}$ Precision Medicine, School of Clinical Sciences at Monash Health, Monash University, Clayton, Victoria, Australia. ${ }^{46}$ Department of Clinical Pathology, The University of Melbourne, Melbourne, Victoria, Australia. ${ }^{47}$ Faculty of Medicine, University of Southampton, Southampton, UK. ${ }^{48}$ Department of Surgery, Leiden University Medical Center, Leiden, The Netherlands. ${ }^{49}$ Department of Pathology, Erasmus MC Cancer Institute, Rotterdam, The Netherlands. ${ }^{50}$ Division of Psychosocial Research and Epidemiology, The Netherlands Cancer Institute - Antoni van Leeuwenhoek Hospital, Plesmanlaan 121, 1066, CX, Amsterdam, The Netherlands. ${ }^{51}$ Leuven Multidisciplinary Breast Center, Department of Oncology, Leuven Cancer Institute, University Hospitals Leuven, Leuven, Belgium. ${ }^{52}$ Department of Clinical Science and Education, Södersjukhuset, Karolinska Institutet, Stockholm, Sweden. ${ }^{53} \mathrm{BOOG}$, Laboratory for Pathology Dordrecht, Dordrecht, The Netherlands.

Received: 7 June 2019 Accepted: 29 October 2019 Published online: 17 December 2019

\section{References}

1. Bray F, Ferlay J, Soerjomataram I, Siegel RL, Torre LA, Jemal A. Global cancer statistics 2018: GLOBOCAN estimates of incidence and mortality worldwide for 36 cancers in 185 countries. CA Cancer J Clin. 2018;68(6):394-424.

2. Survival and prevalence of cancer. https://www.cijfersoverkanker.nl. Accessed Mar 2019.

3. Schaapveld M, Visser O, Louwman WJ, Willemse PH, de Vries EG, van der Graaf WT, Otter R, Coebergh JW, van Leeuwen FE. The impact of adjuvant therapy on contralateral breast cancer risk and the prognostic significance of contralateral breast cancer: a population based study in the Netherlands. Breast Cancer Res Treat. 2008;110(1):189-97.

4. Brenner DJ. Contralateral second breast cancers: prediction and prevention. J Natl Cancer Inst. 2010;102(7):444-5.

5. van den Broek AJ, van 't Veer LJ, Hooning MJ, Cornelissen S, Broeks A, Rutgers EJ, Smit VT, Cornelisse CJ, van Beek M, Janssen-Heijnen ML, et al. Impact of age at primary breast cancer on contralateral breast cancer risk in BRCA1/2 mutation carriers. J Clin Oncol. 2016;34(5):409-18.

6. Malone KE, Begg CB, Haile RW, Borg A, Concannon P, Tellhed L, Xue S, Teraoka S, Bernstein L, Capanu M, et al. Population-based study of the risk of second primary contralateral breast cancer associated with carrying a mutation in BRCA1 or BRCA2. J Clin Oncol. 2010;28(14):2404-10.

7. Evans DG, Ingham SL, Baildam A, Ross GL, Lalloo F, Buchan I, Howell A. Contralateral mastectomy improves survival in women with BRCA1/2associated breast cancer. Breast Cancer Res Treat. 2013;140(1):135-42. 
8. Graeser MK, Engel C, Rhiem K, Gadzicki D, Bick U, Kast K, Froster UG, Schlehe B, Bechtold A, Arnold N, et al. Contralateral breast cancer risk in BRCA1 and BRCA2 mutation carriers. J Clin Oncol. 2009;27(35):5887-92.

9. Weischer M, Nordestgaard BG, Pharoah P, Bolla MK, Nevanlinna H, Van't Veer LJ, Garcia-Closas M, Hopper JL, Hall P, Andrulis IL, et al. CHEK2*1100delC heterozygosity in women with breast cancer associated with early death, breast cancer-specific death, and increased risk of a second breast cancer. J Clin Oncol. 2012;30(35):4308-16.

10. Kuchenbaecker KB, Hopper IL, Barnes DR, Phillips KA, Mooij TM, Roos-Blom MJ, Jervis S, van Leeuwen FE, Milne RL, Andrieu N, et al. Risks of breast, ovarian, and contralateral breast cancer for BRCA1 and BRCA2 mutation carriers. JAMA. 2017;317(23):2402-16.

11. Domchek SM. Risk-reducing mastectomy in BRCA1 and BRCA2 mutation carriers: a complex discussion. JAMA. 2019;321(1):27.

12. Chen Y, Thompson W, Semenciw R, Mao Y. Epidemiology of contralateral breast cancer. Cancer Epidemiol Biomark Prev. 1999;8(10):855-61.

13. Kramer I, Schaapveld M, Oldenburg HSA, Sonke GS, McCool D, van Leeuwen FE, Van de Vijver KK, Russell NS, Linn SC, Siesling S, et al. The influence of adjuvant systemic regimens on contralateral breast cancer risk and receptor subtype. J Natl Cancer Inst. 2019;111(7):709-18.

14. Portschy PR, Abbott AM, Burke EE, Nzara R, Marmor S, Kuntz KM, Tuttle TM Perceptions of contralateral breast cancer risk: a prospective, longitudinal study. Ann Surg Oncol. 2015;22(12):3846-52.

15. Murphy JA, Milner TD, O'Donoghue JM. Contralateral risk-reducing mastectomy in sporadic breast cancer. Lancet Oncol. 2013;14(7):e262-9.

16. Chowdhury M, Euhus D, Onega T, Biswas S, Choudhary PK. A model for individualized risk prediction of contralateral breast cancer. Breast Cancer Res Treat. 2017;161(1):153-60.

17. Chowdhury M, Euhus D, Arun B, Umbricht C, Biswas S, Choudhary P. Validation of a personalized risk prediction model for contralateral breast cancer. Breast Cancer Res Treat. 2018;170:415. https://ink.springer.com/ article/10.1007/s10549-018-4763-5\#citeas.

18. Vickers AJ, Van Calster B, Steyerberg EW. Net benefit approaches to the evaluation of prediction models, molecular markers, and diagnostic tests. BMJ. 2016;352:i6.

19. Michailidou K, Lindstrom S, Dennis J, Beesley J, Hui S, Kar S, Lemacon A, Soucy P, Glubb D, Rostamianfar A, et al. Association analysis identifies 65 new breast cancer risk loci. Nature. 2017:551(7678):92-4.

20. Schmidt MK, Tollenaar RA, de Kemp SR, Broeks A, Cornelisse CJ, Smit VT, Peterse $\mathrm{JL}$, van Leeuwen FE, Van't Veer LJ. Breast cancer survival and tumor characteristics in premenopausal women carrying the CHEK2*1100delC germline mutation. J Clin Oncol. 2007;25(1):64-9.

21. Schmidt MK, van den Broek AJ, Tollenaar RA, Smit VT, Westenend PJ, Brinkhuis M, Oosterhuis WJ, Wesseling J, Janssen-Heijnen ML, Jobsen J, et al. Breast cancer survival of BRCA1/BRCA2 mutation carriers in a hospitalbased cohort of young women. J Natl Cancer Inst. 2017;109(8). https:// academic.oup.com/jnci/article/109/8/djw329/3064570.

22. Font-Gonzalez A, Liu L, Voogd AC, Schmidt MK, Roukema JA, Coebergh JW, de Vries E, Soerjomataram I. Inferior survival for young patients with contralateral compared to unilateral breast cancer: a nationwide populationbased study in the Netherlands. Breast Cancer Res Treat. 2013;139(3):811-9.

23. Riegman PH, van Veen EB. Biobanking residual tissues. Hum Genet. 2011;130(3):357-68.

24. Foundation Federation of Dutch Medical Scientific Societies: Human tissue and medical research: code of conduct for responsible use. 2011.

25. Vichapat V, Garmo H, Holmqvist M, Liljegren G, Warnberg F, Lambe M, Fornander T, Adolfsson J, Luchtenborg M, Holmberg L. Tumor stage affects risk and prognosis of contralateral breast cancer: results from a large Swedish-population-based study. J Clin Oncol. 2012;30(28):3478-85.

26. Vichapat V, Gillett C, Fentiman IS, Tutt A, Holmberg L, Luchtenborg M. Risk factors for metachronous contralateral breast cancer suggest two aetiological pathways. Eur J Cancer. 2011;47(13):1919-27.

27. Mariani L, Coradini D, Biganzoli E, Boracchi P, Marubini E, Pilotti S, Salvadori B, Silvestrini $R$, Veronesi U, Zucali $R$, et al. Prognostic factors for metachronous contralateral breast cancer: a comparison of the linear Cox regression model and its artificial neural network extension. Breast Cancer Res Treat. 1997;44(2):167-78.

28. Reiner AS, Lynch CF, Sisti JS, John EM, Brooks JD, Bernstein L, Knight JA, Hsu $L$, Concannon $P$, Mellemkjaer $L$, et al. Hormone receptor status of a first primary breast cancer predicts contralateral breast cancer risk in the WECARE study population. Breast Cancer Res. 2017;19(1):83.
29. Sisti JS, Bernstein JL, Lynch CF, Reiner AS, Mellemkjaer L, Brooks JD, Knight JA, Bernstein L, Malone KE, Woods M, et al. Reproductive factors, tumor estrogen receptor status and contralateral breast cancer risk: results from the WECARE study. Springerplus. 2015:4:825.

30. Healey EA, Cook EF, Orav EJ, Schnitt SJ, Connolly JL, Harris JR. Contralateral breast cancer: clinical characteristics and impact on prognosis. J Clin Oncol. 1993;11(8):1545-52.

31. Gao X, Fisher SG, Emami B. Risk of second primary cancer in the contralateral breast in women treated for early-stage breast cancer: a population-based study. Int J Radiat Oncol Biol Phys. 2003;56(4):1038-45

32. Brooks JD, John EM, Mellemkjaer L, Lynch CF, Knight JA, Malone KE, Reiner AS, Bernstein L, Liang X, Shore RE, et al. Body mass index, weight change, and risk of second primary breast cancer in the WECARE study: influence of estrogen receptor status of the first breast cancer. Cancer Med. 2016;5(11):3282-91.

33. Knight JA, Blackmore KM, Fan J, Malone KE, John EM, Lynch CF, Vachon CM, Bernstein L, Brooks JD, Reiner AS, et al. The association of mammographic density with risk of contralateral breast cancer and change in density with treatment in the WECARE study. Breast Cancer Res. 2018;20(1):23.

34. Basu NN, Barr L, Ross GL, Evans DG. Contralateral risk-reducing mastectomy: review of risk factors and risk-reducing strategies. Int J Surg Oncol. 2015; 2015:901046.

35. Akdeniz D, Schmidt MK, Seynaeve CM, McCool D, Giardiello D, van den Broek AJ, Hauptmann M, Steyerberg EW, Hooning MJ. Risk factors for metachronous contralateral breast cancer: a systematic review and metaanalysis. Breast. 2018;44:1-14

36. Edge SB, Compton CC. The American Joint Committee on Cancer: the 7th edition of the AJCC cancer staging manual and the future of TNM. Ann Surg Oncol. 2010;17(6):1471-4.

37. R Core Team. R: A language and environment for statistical computing. R Foundation for Statistical Computing, Vienna, Austria. 2017. http://www.Rproject.org/, https://cran.r-project.org/doc/FAQ/R-FAQ.html\#Citing-R.

38. van den Broek AJ, Schmidt MK, van 't Veer LJ, HSA O, Rutgers EJ, Russell NS, Smit V, Voogd AC, Koppert LB, Siesling S, et al. Prognostic impact of breastconserving therapy versus mastectomy of BRCA1/2 mutation carriers compared with noncarriers in a consecutive series of young breast cancer patients. Ann Surg. 2019;270(2):364-72.

39. Resche-Rigon M, White IR, Bartlett JW, Peters SA, Thompson SG, Group P-IS. Multiple imputation for handling systematically missing confounders in meta-analysis of individual participant data. Stat Med. 2013;32(28):4890-905.

40. Sv B. Flexible imputation of missing data. Boca Raton: CRC Press; 2012.

41. Geskus RB. Cause-specific cumulative incidence estimation and the fine and gray model under both left truncation and right censoring. Biometrics. 2011;67(1):39-49.

42. Fine JP, Gray RJ. A proportional hazards model for the subdistribution of a competing risk. J Am Stat Assoc. 1999;94(446):496-509.

43. Schoenfeld DA. Sample-size formula for the proportional-hazards regression model. Biometrics. 1983;39(2):499-503.

44. Little RJA, Rubin DB. Statistical analysis with missing data. New York: Wiley; 1987.

45. Zhang Z, Geskus RB, Kattan MW, Zhang H, Liu T. Nomogram for survival analysis in the presence of competing risks. Ann Transl Med. 2017;5(20):403.

46. Steyerberg EW, Harrell FE Jr. Prediction models need appropriate internal, internal-external, and external validation. J Clin Epidemiol. 2016;69:245-7.

47. Austin PC, van Klaveren D, Vergouwe Y, Nieboer D, Lee DS, Steyerberg EW. Geographic and temporal validity of prediction models: different approaches were useful to examine model performance. J Clin Epidemiol. 2016;79:76-85.

48. Collins GS, Ogundimu EO, Altman DG. Sample size considerations for the external validation of a multivariable prognostic model: a resampling study. Stat Med. 2016;35(2):214-26.

49. Steyerberg EW. Clinical prediction models: a practical approach to development, validation and updating. New York: Springer; 2010.

50. Blanche P, Dartigues JF, Jacqmin-Gadda H. Estimating and comparing timedependent areas under receiver operating characteristic curves for censored event times with competing risks. Stat Med. 2013;32(30):5381-97.

51. Snell KI, Hua H, Debray TP, Ensor J, Look MP, Moons KG, Riley RD. Multivariate meta-analysis of individual participant data helped externally validate the performance and implementation of a prediction model. J Clin Epidemiol. 2016;69:40-50.

52. Vickers AJ, Elkin EB. Decision curve analysis: a novel method for evaluating prediction models. Med Decis Mak. 2006;26(6):565-74. 
53. Kerr KF, Brown MD, Zhu K, Janes $H$. Assessing the clinical impact of risk prediction models with decision curves: guidance for correct interpretation and appropriate use. J Clin Oncol. 2016;34(21):2534-40.

54. Vickers AJ, Cronin AM, Elkin EB, Gonen M. Extensions to decision curve analysis, a novel method for evaluating diagnostic tests, prediction models and molecular markers. BMC Med Inform Decis Mak. 2008:8:53.

55. Heemskerk-Gerritsen BA, Rookus MA, Aalfs CM, Ausems MG, Collee JM, Jansen L, Kets CM, Keymeulen KB, Koppert LB, Meijers-Heijboer HE, et al. Improved overall survival after contralateral risk-reducing mastectomy in BRCA1/2 mutation carriers with a history of unilateral breast cancer: a prospective analysis. Int J Cancer. 2015;136(3):668-77.

56. Rockhill B, Spiegelman D, Byrne C, Hunter DJ, Colditz GA. Validation of the Gail et al. model of breast cancer risk prediction and implications for chemoprevention. J Natl Cancer Inst. 2001;93(5):358-66.

57. Elmore JG, Fletcher SW. The risk of cancer risk prediction: "what is my risk of getting breast cancer"? J Natl Cancer Inst. 2006;98(23):1673-5.

58. Wishart GC, Azzato EM, Greenberg DC, Rashbass J, Kearins O, Lawrence G, Caldas C, Pharoah PD. PREDICT: a new UK prognostic model that predicts survival following surgery for invasive breast cancer. Breast Cancer Res. 2010;12(1):R1.

59. Goldstein LJ, Gray R, Badve S, Childs BH, Yoshizawa C, Rowley S, Shak S, Baehner FL, Ravdin PM, Davidson NE, et al. Prognostic utility of the 21-gene assay in hormone receptor-positive operable breast cancer compared with classical clinicopathologic features. J Clin Oncol. 2008;26(25):4063-71.

60. van den Broek AJ, de Ruiter $K$, van 't Veer $L$, Tollenaar RA, van Leeuwen FE, Verhoef S, Schmidt MK. Evaluation of the Dutch BRCA1/2 clinical genetic center referral criteria in an unselected early breast cancer population. Eur J Hum Genet. 2015;23(5):588-95.

61. Gail MH, Pfeiffer RM. Breast cancer risk model requirements for counseling, prevention, and screening. J Natl Cancer Inst. 2018;110(9):994-1002.

62. O'Donnell M. Estimating contralateral breast cancer risk. Current Breast Cancer Rep. 2018;10(2):91-7.

63. van Maaren MC, de Munck L, Strobbe LA, Sonke GS, Westenend PJ, Smidt ML, Poortmans PMP, Siesling S. Ten-year recurrence rates for breast cancer subtypes in the Netherlands: a large population-based study. Int J Cancer. 2019;144(2):263-72.

64. Lu W, Schaapveld M, Jansen L, Bagherzadegan E, Sahinovic MM, Baas PC, Hanssen LM, van der Mijle HC, Brandenburg JD, Wiggers T, et al. The value of surveillance mammography of the contralateral breast in patients with a history of breast cancer. Eur J Cancer. 2009;45(17):3000-7.

65. Xiong Z, Yang L, Deng G, Huang X, Li X, Xie X, Wang J, Shuang Z, Wang X. Patterns of occurrence and outcomes of contralateral breast cancer: analysis of SEER data. J Clin Med. 2018;7(6):133. https://www.ncbi.nlm.nih.gov/pmc/ articles/PMC6025574/.

66. Langballe R, Mellemkjaer L, Malone KE, Lynch CF, John EM, Knight JA, Bernstein L, Brooks J, Andersson M, Reiner AS, et al. Systemic therapy for breast cancer and risk of subsequent contralateral breast cancer in the WECARE study. Breast Cancer Res. 2016;18(1):65.

67. Basu NN, Ross GL, Evans DG, Barr L. The Manchester guidelines for contralateral risk-reducing mastectomy. World J Surg Oncol. 2015;13:237.

68. Nieboer D, Vergouwe Y, Ankerst DP, Roobol MJ, Steyerberg EW. Improving prediction models with new markers: a comparison of updating strategies. BMC Med Res Methodol. 2016;16(1):128.

69. Collins GS, Altman DG. Predicting the 10 year risk of cardiovascular disease in the United Kingdom: independent and external validation of an updated version of QRISK2. BMJ. 2012;344:e4181.

70. Madley-Dowd P, Hughes R, Tilling K, Heron J. The proportion of missing data should not be used to guide decisions on multiple imputation. J Clin Epidemiol. 2019;110:63-73.

71. Childers CP, Childers KK, Maggard-Gibbons M, Macinko J. National estimates of genetic testing in women with a history of breast or ovarian cancer. J Clin Oncol. 2017;35(34):3800-6.

72. Bonnett LJ, Snell KIE, Collins GS, Riley RD. Guide to presenting clinical prediction models for use in clinical settings. BMJ. 2019;365:1737.

73. Van Belle V, Van Calster B. Visualizing risk prediction models. PLoS One. 2015:10(7):e0132614

74. Balachandran VP, Gonen M, Smith JJ, DeMatteo RP. Nomograms in oncology: more than meets the eye. Lancet Oncol. 2015;16(4):e173-80.

75. Mavaddat N, Michailidou K, Dennis J, Lush M, Fachal L, Lee A, Tyrer JP, Chen TH, Wang Q, Bolla MK, et al. Polygenic risk scores for prediction of breast cancer and breast cancer subtypes. Am J Hum Genet. 2019;104(1):21-34.

\section{Publisher's Note}

Springer Nature remains neutral with regard to jurisdictional claims in published maps and institutional affiliations.
Ready to submit your research? Choose BMC and benefit from:

- fast, convenient online submission

- thorough peer review by experienced researchers in your field

- rapid publication on acceptance

- support for research data, including large and complex data types

- gold Open Access which fosters wider collaboration and increased citations

- maximum visibility for your research: over $100 \mathrm{M}$ website views per year

At BMC, research is always in progress.

Learn more biomedcentral.com/submissions 